\title{
Co-morbidity is the norm, not the exception: chronic respiratory diseases in chronic drug users
}

See linked article by Palmer et al. on pg 377

\section{*Theresa W Kim¹, Jeffrey H Samet ${ }^{1,2}$}

1 Department of Medicine, Section of General Internal Medicine, Clinical Addiction Research and Education (CARE) Unit, Boston University School of Medicine/Boston Medical Center, Boston, Massachusetts, USA

2 Department of Community Health Sciences, Boston University School of Public Health, Boston, Massachusetts, USA

*Correspondence: Dr Theresa W Kim, MD, 801 Massachusetts Ave., 2nd Floor, Boston, MA 02118, USA

Tel: +1 (617) 414-6932 Fax: +1 (617) 414-4676

E-mail: theresa.kim@bmc.org

Individuals with chronic drug use disorders frequently have medical co-morbidities. ${ }^{1,2}$ Mertens et al. documented the high prevalence of chronic medical conditions and its associated significant morbidity among insured patients in a specialty alcohol and drug treatment clinic. ${ }^{3}$ Among alcohol or drug dependent patients on the opposite end of the socioeconomic spectrum in the USA - those without primary care who were entering residential detoxification - $45 \%$ reported having a chronic medical illness. ${ }^{1}$ One third of a comparable group reported being in fair or poor health. ${ }^{4}$ Thus, it is fair to say that co-morbidity, among the socioeconomic spectrum of chronic drug users in care, is the norm, not the exception.

Despite an expanding literature on medical co-morbidities among drug using populations, respiratory diseases have not been wellstudied. The bulk of the literature on drug users and respiratory disease has focused on infectious complications of drug use, including bacterial pneumonia, septic pulmonary embolism, and tuberculosis (TB). ${ }^{5,6}$ These medical conditions are acute or sub-acute (e.g. TB) episodic illnesses. Chronic, non-infectious respiratory diseases such as asthma and chronic obstructive pulmonary disease (COPD) among drug users have not been well-characterised. Studies demonstrating the effectiveness of disease management programmes for chronic medical conditions such as asthma typically exclude individuals with drug use. ${ }^{7}$ However, a better understanding of the risks of chronic respiratory diseases would inform efforts to improve the medical assessment and treatment - both therapeutic and preventive - of patients who are also drug users. Such work would address a treatment gap for a population less likely to receive quality asthma care $^{7}$ and flu vaccination. ${ }^{8}$

In this issue of the $P C R J$, Palmer et al. report on respiratory diseases in drug users. ${ }^{9}$ Specifically, they performed a cross-sectional analysis of the association of chronic respiratory diseases and "drug misuse" using administrative data collected from general practices in Scotland. The authors found that drug users were more likely to have a diagnosis of chronic respiratory diseases (i.e. asthma, COPD, and "respiratory system disease") than a control group matched for age, gender, and economic status. Drug users were also more likely to be prescribed respiratory medications, primarily bronchodilators and inhaled corticosteroids. These associations did not appear to be fully attributable to the high prevalence of tobacco use, since these differences persisted with adjustment for tobacco use. This study's results are consistent with others in the literature, ${ }^{1-4}$ and Palmer et al. substantively contribute to this literature by performing their analysis on a national database. ${ }^{9}$ Additionally, the use of a control group matched on key socio-demographic variables strengthens the research design.

Nonetheless, interpretation of study findings requires consideration of study limitations. First, substance type was unknown in nearly three-quarters of cases (72\%), making it difficult to assess what accounts for the relationship between drug use and respiratory disease. Second, chronic respiratory disease was defined as ever having a diagnosis of asthma, COPD, or "respiratory system disease" since birth; therefore it is unknown whether the respiratory disease predated the onset of drug use. Third, although the exact number of opioid users in the study is unknown, some portion of the drug "misuser" sample consisted of patients prescribed methadone for opioid dependence from general practices, which may have required frequent office visits; therefore, respiratory diseases may have been more likely to be detected given the increased surveillance among these patients.

Despite these caveats, the study raises useful questions and suggests pragmatic implications. As noted among other studies of drug users, tobacco use in this study's sample ${ }^{9}$ was almost universal $(90 \%)$. Although the findings may not have been fully attributable to tobacco use, tobacco is still the major driver responsible for respiratory disease in this population. From a clinical perspective, given that COPD is typically under-diagnosed and under-treated in primary care, ${ }^{10}$ these findings, although not definitive, should raise awareness that individuals with drug addiction are at high risk of chronic respiratory diseases. From a research perspective, determining whether or not contributors other than tobacco exist would be of value, as it might enable medical teams pro-actively to direct attention to other useful evaluation and treatment.

Evidence of an increased risk of chronic respiratory diseases among drug users also enhances the case for the coordination of care between addiction treatment providers and those addressing these patients' chronic medical conditions. ${ }^{11}$ Drug treatment is an opportunity for the patient not only to address drug use but also to consider the wider health consequences of drug use including respiratory illness and linking patients to medical care. ${ }^{12,13}$ Raising the issue with the patient and making a plan to address this common diagnosis might serve not only to improve their health and quality of life but could build the rationale for the patient to make recovery a priority. Weisner et al. demonstrated improved addiction outcomes 
with integrated addiction and medical treatment for those with chronic medical conditions. ${ }^{14}$

This examination of respiratory diseases among drug users ${ }^{9}$ adds further strength to the premise that, given the frequency of overlapping drug use and medical co-morbidities, improvements in these health domains will likely require health professionals to be cognisant of both, in the quest to address either optimally.

Conflicts of interest The authors declare that they have no conflicts of interest in relation to this article.

Contributorship Both authors have contributed significantly to the writing and editing of the manuscript, and have approved this manuscript.

Commissioned article; not externally peer-reviewed; accepted 28th October 2012; online 8th November 2012

(c) 2012 Primary Care Respiratory Society UK. All rights reserved

http://dx.doi.org/10.4104/pcrj.2012.00094

Prim Care Respir J 2012; 21(4): 364-365

\section{References}

1. De Alba, Samet JH, Saitz R. Burden of medical illness in drug- and alcoholdependent persons without primary care. Am J Addict 2004;13(1):33-45 http://dx.doi.org/l10.1080/10550490490265307

2. Fareed A, Musselman D, Byrd-Sellers J, et al. On-site Basic Health Screening and Brief Health Counseling of Chronic Medical Conditions for Veterans in Methadone Maintenance Treatment. J Addict Med 2010;4(3):160-6.

http://dx.doi.org/10.1097/ADM.0b013e3181b6f4e5

3. Mertens JR, Lu YW, Parthasarathy S, Moore C, Weisner CM. Medical and psychiatric conditions of alcohol and drug treatment patients in an HMO: comparison with matched controls. Arch Intern Med 2003;163(20):2511-17. http://dx.doi.org/10.1001/archinte.163.20.2511

4. Reif S, Larson MJ, Cheng DM, Allensworth-Davies D, Samet J, Saitz R. Chronic disease and recent addiction treatment utilization among alcohol and drug dependent adults. Subst Abuse Treat Prev Policy 2011;6:28.
http://dx.doi.org/10.1186/1747-597X-6-28

5. O'Donnell AE, Pappas LS. Pulmonary complications of intravenous drug abuse. Experience at an inner-city hospital. Chest 1988;94(2):251-3. http://dx.doi.org/10.1378/chest.94.2.251

6. Gordon RJ, Lowy FD. Bacterial infections in drug users. N Engl I Med 2005;353(18):1945-54. http://dx.doi.org/10.1056/NEJMra042823

7. Baxter JD, Samnaliev M, Clark RE. The quality of asthma care among adults with substance-related disorders and adults with mental illness. Psychiatr Serv 2009;60(1):43-9. http://dx.doi.org/10.1176/appi.ps.60.1.43

8. Lasser KE, Kim TW, Alford DP, Cabral H, Saitz R, Samet JH. Is unhealthy substance use associated with failure to receive cancer screening and flu vaccination? A retrospective cross-sectional study. BMJ Open 2011;1(1):e000046. http://dx.doi.org/10.1136/bmjopen-2010-000046

9. Palmer F, Jaffray M, Moffat MA, Matheson C, McLernon DJ, Coutts A, Haughney J. Prevalence of common chronic respiratory diseases in drug misusers: a cohort study. Prim Care Respir J 2012;21(4):377-83. http://dx.doi.org/10.4104/pcrj.2012.00069

10. Jones $R$, Østrem A. Optimising pharmacological maintenance treatment for COPD in primary care. Prim Care Respir J 2011;20(1):33-45. http://dx.doi.org/10.4104/pcri.2010.00069

11. Institute of Medicine. Improving the Quality of Health Care for Mental and Substance-Use Conditions: Quality Chasm Series. 1st ed. National Academies Press; 2006.

12. Samet JH, Friedmann P, Saitz R. Benefits of linking primary medical care and substance abuse services: patient, provider, and societal perspectives. Arch Intern Med 2001;161(1):85-91.

http://dx.doi.org/10-1001/pubs.Arch Intern Med.-ISSN-0003-9926-161-1-ioi00065.

13. Samet JH, Larson MJ, Horton NJ, Doyle K, Winter M, Saitz R. Linking alcohol- and drug-dependent adults to primary medical care: a randomized controlled trial of a multi-disciplinary health intervention in a detoxification unit. Addiction 2003;98(4):509-16. http://dx.doi.org/10.1046/j.1360-0443.2003.00328.x

14. Weisner C, Mertens J, Parthasarathy S, Moore C, Lu Y. Integrating primary medical care with addiction treatment: a randomized controlled trial. JAMA 2001;286(14):1715-23. http://dx.doi.org/10.1001/jama.286.14.1715

\section{Adolescents and anaphylaxis}

\section{See linked article by Gallagher et al. on pg 392}

\section{*Richard F Lockey}

1 Distinguished University Health Professor; Professor of Medicine, Pediatrics \& Public Health; Director, Division of Allergy \& Immunology; Joy McCann Culverhouse Professor of Allergy \& Immunology, University of South Florida College of Medicine, USA

*Correspondence: Professor Richard F Lockey, Culverhouse Professor of Allergy \& Immunology, University of South Florida College of Medicine, c/o VA Hospital, 13000 Bruce B.Downs Blvd (111D), Tampa, FL 33612, USA

Tel: +1 (813) 972-7631 Fax: +1 (813) 910-4041

E-mail: rlockey@health.usf.edu

The article by Gallagher et al. ${ }^{1}$ in this issue of the $P C R J$ is of particular interest, not least because the authors studied 26 adolescents (aged 13 to 19 years) at risk for anaphylaxis and did not find the "rebel without a cause" mentality as the dominant reason why this age group is three to four times more likely to die than children because they take risks and have accidents. ${ }^{2}$ The movie, "Rebel Without a Cause", starring James Dean, was released by Warner Bros on 27th October 1955, less than one month after the famous actor's fatal car crash. In this controversial movie of the time, Jim Stark (played by James Dean) is a rebellious 17-year-old teenager caught up in family discord who disobeys his parents, defies the local schoolboys, and confronts the differences and conflicts between generations. ${ }^{3}$ One would think that teenagers susceptible to anaphylaxis would possess the James Dean-like rebellious personality, thereby accounting for the fact that adolescents with this disease are at increased risk of fatal outcomes.

However, just the opposite was found in this study. The majority of episodes of anaphylaxis, primarily from food allergies (in particular, peanuts and tree nuts) but also due to fish, shellfish, sesame seed, dairy, lentils, milk, egg, tomato and other fleshy fruits, legumes and insects, horse and idiopathic, "...did not result from stereotypically irresponsible behavior (such as alcohol misuse or deliberate exposure to known allergens)."1 The authors found that most adolescents, as did their parents, took an active role in managing their risk of anaphylaxis. Some parents and adolescents emphasised the idea that 